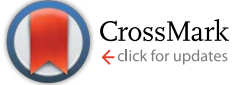

Cite this: RSC Adv., 2016, 6, 53303

\title{
Biocompatible anti-microbial coatings for urinary catheters $\uparrow$
}

\author{
Vanessa C. Thompson, ${ }^{a}$ Penelope J. Adamson, ${ }^{b}$ Jessirie Dilag, $\dot{t}^{\mathrm{a}}$ \\ Dhanushka Bandara Uswatte Uswatte Liyanage, ${ }^{a}$ Kagithiri Srikantharajah, ${ }^{\text {ac }}$ \\ Andrew Blok, ${ }^{a}$ Amanda V. Ellis, ${ }^{a}$ David L. Gordon ${ }^{b}$ and Ingo Köper*a \\ Using a simple dip-coating mechanism, urinary catheters have been coated with poly(2- \\ methacryloyloxyethyl)trimethylammonium chloride (pMTAC) using activator regenerated by electron \\ transfer (ARGET)-atom transfer radical polymerization (ATRP). A polydopamine-2-bromoisobutyryl \\ bromide ( $\mathrm{pDA}-\mathrm{BiBBr})$ initiator was initially grafted to the catheter surface to initiate polymerization \\ resulting in a pDA-g-pMTAC coating. The pDA-g-pMTAC-coated catheters showed a significant \\ reduction in bacterial adhesion, with respect to uncoated silicone catheters, as determined by analyzing \\ microbiological assays as well as scanning electron microscopy images. At the same time, no evidence \\ for cytotoxicity was observed, rather, the coating promoted cell adhesion and proliferation of human \\ cells. This makes the coating attractive for temporary as well as permanently implanted medical devices.
}

Received 24th March 2016 Accepted 24th May 2016

DOI: $10.1039 / \mathrm{c} 6 \mathrm{ra0} 076 \mathrm{e}$

www.rsc.org/advances reduce bacterial adhesion and biofilm formation by chemical modification of the surface of the foreign material. ${ }^{4}$

Historically, catheters have been made from latex, which is toxic to cells of the urinary tract, ${ }^{5}$ and the development of silicone-coated latex or pure silicone catheters has led to a reduction in catheter associated urinary tract infections. ${ }^{6}$ In order to further decrease biofilm formation, catheter surfaces have been modified by the addition silver, ${ }^{7}$ nitrofurazone, ${ }^{8,9}$ or antibiotics. ${ }^{10}$ For silver coatings, the in vitro results have been inconsistent, with some tests showing no difference in biofilm development compared to untreated catheters. ${ }^{8,9}$ In addition, no significant decrease in catheter associated urinary tract infections was observed when silver-treated catheters were used in large clinical trials. ${ }^{11,12}$ An alternative approach in surface coatings has been the use of nitrofurazone, which releases nitrous oxide (NO) as an active agent mimicking the natural immune reaction. However, the antibacterial potency lasted only five days in in vitro studies. ${ }^{13}$ Antibiotics such as such as ciprofloxacin, ${ }^{14}$ thiazolidinediones, ${ }^{15}$ and triclosan,${ }^{16}$ have been attached to catheter surfaces, mainly using polymers as binding agents. While these approaches have shown an effective prevention of biofilms, antibiotic resistance can develop easily in bacteria. $^{17}$

Besides their use as adhesive agents, polymers have also been used as active antifouling components. Cationic charges from quaternary ammonium salts and other functional groups can be effective antimicrobial agents; however, there can be celltype specific toxicity to mammalian cells,${ }^{18}$ depending on the specific quaternary ammonium compound used. ${ }^{19,20}$ Hydrophilic polymers can also prevent bacterial attachment, and the use of hydrophilic, PEG- $b$-cationic polycarbonate diblock- ${ }^{21}$ and

\footnotetext{
Flinders Centre for NanoScale Science and Technology, and School of Chemical and Physical Sciences, Flinders University, Bedford Park, SA 5042, Australia. E-mail: ingo.koeper@flinders.edu.au

${ }^{b}$ Department of Microbiology and Infectious Diseases, Flinders University, Flinders Medical Centre, Bedford Park, SA 5042, Australia

${ }^{c}$ University of Applied Sciences Kaiserslautern, 66482 Zweibrücken, Germany

$\dagger$ Electronic supplementary information (ESI) available: ATR-FTIR, WCA, colony counts. See DOI: 10.1039/c6ra07678e

\$ Currently at: School of Aerospace, Mechanical and Manufacturing Engineering, RMIT University, Melbourne VIC 3000, Australia.
} 
triblock-copolymers ${ }^{22}$ as surface coatings has been effective in preventing surface fouling and inhibiting bacterial growth. Polymers with cyclic hydrocarbon groups ${ }^{23}$ and histidine copolymer-based nanostructured coatings have also been shown to decrease biofouling. ${ }^{24}$ Mixed cationic copolymers with polyethylene glycol and quaternary amine functional groups have shown antimicrobial activity for up to seven days with minimal fouling under in vitro conditions. ${ }^{21}$

While polymeric coatings on catheters have shown promising results, a major challenge is long-term stability under in vivo conditions. Polymeric coatings can lose their efficacy by degradation of the material, loss of functional groups, structural rearrangements of the polymer, which remove functional groups from the polymer surface, or a loss of the coating. ${ }^{25}$

Here, dopamine derivative coatings for the engraftment of an anti-biofouling polymer have been used to modify the surface of a silicone-based urinary catheter. Polydopamine (pDA) can coat different types of surfaces ${ }^{26}$ and can itself be further modified to attach functional polymers. Using the inherent "stickiness" of pDA can ultimately increase the polymer coating efficacy, by maintaining structural and functional integrity. ${ }^{27-30}$

Here, DA has been modified with an initiator, and the resulting pDA-initiator polymer has been used to engraft poly[2(methacryloyloxy)ethyl]trimethylammonium chloride (pMTAC) onto silicone catheters. This strategy has recently been shown effective in preventing biofouling of polyamide desalination membranes..$^{31,32}$

The engrafted polymer, comprised of monomers each containing an active anti-biofouling functional group, provided two major benefits over end-functionalized polymers. Degradation of the polymer coating will reveal only more of the same active functional groups, and polymer chain end groups do not need to be exposed, as each monomer possesses a functional group.

The pDA- $g$-pMTAC coatings resulted in a significant reduction of bacterial adhesion to catheters. Additionally, the coatings proved to be non-cytotoxic and rather promoted adhesion and proliferation of human cells, making the architecture an intriguing coating for medical devices.

\section{Materials and methods}

\section{Materials}

Ascorbic acid, copper(II) chloride $\left(\mathrm{CuCl}_{2}, 97 \%\right)$, dopamine (DA) hydrochloride, ethanol, Hellmanex, triethylamine (TEA), tris(2pyridylmethyl)amine (TPMA), 2-bromoisobutyryl bromide (BiBBr), [2-(methacryloyloxy)ethyl]trimethylammonium chloride (MTAC), sodium azide and paraformaldehyde were purchased from Sigma-Aldrich, Australia, and used as received unless otherwise stated. Isopropanol and methanol were purchased from Merck, and used without further purification. Dulbecco's Modified Eagle Medium (DMEM), L-glutamate, and phosphate buffered saline (PBS) were purchased from In Vitro Technologies, Australia. Fetal bovine serum (FBS) was purchased from Bovogen Biologicals, Australia. Brain Heart Infusion (BHI) broth and Trypticase Soy Agar (TSA) were purchased from Thermo Fisher Scientific, Australia. Tissue culture cell lines, Vero and HEK293, were purchased from ATCC, USA. Concentrated nitric acid $\left(\mathrm{HNO}_{3}\right)$ and hydrogen peroxide $\left(\mathrm{H}_{2} \mathrm{O}_{2}\right)$ were purchased from Choice Analytical, Australia. Gold metal was purchased from ProSciTech, Australia. Ultrapure water (Millipore, $>18 \mathrm{M} \Omega \mathrm{cm}$ ) was used unless otherwise stated.

Surface modification of catheters and glass microscope slides. Dopamine-2-bromoisobutyryl bromide (DA-BiBBr) initiator was prepared following an adaptation of Blok et al. ${ }^{31}$ Dopamine hydrochloride (400 $\mathrm{mg}, 2.10 \mathrm{mmol}$ ) was stirred under nitrogen for $5 \mathrm{~min}$. Ultrapure water $(20 \mathrm{~mL})$ was added via syringe and the solution was degassed under nitrogen for at least $20 \mathrm{~min}$. TEA $(0.13 \mathrm{~mL}, 0.91 \mathrm{mmol})$ and $\mathrm{BiBBr}(0.13 \mathrm{~mL}$, $1.05 \mathrm{mmol}$ ) were added and the solution left to stir under nitrogen for $3 \mathrm{~h}$, at room temperature. The product, DA-BiBBr, was stored under nitrogen in the dark until further use or characterization.

Catheter pieces (Silicone Elastomer Coated Foley Catheter 20 Ch/Fr, Bard, Covington, GA, USA) or glass microscope slides (pathology grade, Livingstone, Australia); cut to size (typically about $1 \mathrm{~cm}$ lengths for catheters and half a slide for glass slides) and cleaned with $2 \%$ Hellmanex, were placed into concentrated Tris buffer solution (450 mg, tris(hydroxymethyl)aminomethane (Tris) dissolved in $80 \mathrm{~mL}$ of ultrapure water) and gently stirred for $5 \mathrm{~min}$. DA-BiBBr $(20 \mathrm{~mL})$ was filtered through filter paper to remove particulates, then added to the Tris buffer solution containing either the catheter or glass slide samples (final pH 8.5, final Tris concentration $0.04 \mathrm{M}$ ) and left to stir for $24 \mathrm{~h}$ in air. The resulting pDA-BiBBr coated samples were removed, rinsed twice with $100 \mathrm{~mL}$ Tris buffer and dried under nitrogen (Scheme 1, Step(i)).

Surface initiated activator regeneration by electron transferatom transfer radical polymerization (ARGET-ATRP) of MTAC from the pDA-BiBBr coated surface. The pDA-BiBBr coated samples were added to an aqueous solution of MTAC monomer ( $8 \mathrm{~g}$ in $150 \mathrm{~mL}$ ultrapure water) in a sealed, two-necked round bottom flask (for catheter samples) or a sealed Coplin jar (for glass slide samples) under a nitrogen atmosphere. For the glass slide samples, the polymerization solution covered only the lower half of the surface to allow for direct comparisons between the pDA-BiBBr and pDA- $g$-pMTAC coatings. The vessels were degassed under nitrogen via syringe for $1 \mathrm{~h}$. $\mathrm{Cu}(\mathrm{II}) \mathrm{Cl}_{2}$ catalyst $(0.001 \mathrm{~g})$ and TPMA ligand $(0.04 \mathrm{~g})$ were dissolved in a solution of ultrapure water in isopropanol (1:10, v/v, $10 \mathrm{~mL}$ ), then $10 \mathrm{~mL}$ of this solution were added to the vessel via syringe. The solution was stirred under nitrogen for 20 min followed by the addition of ascorbic acid ( $0.6 \mathrm{~g}$ in $10 \mathrm{~mL}$ of ultrapure water). The polymerization reaction was left to stir under nitrogen for $24 \mathrm{~h}$. Exposure to air terminated polymerization. The resulting pDA- $g$-pMTAC-coated samples were removed and rinsed with water, dried under nitrogen and stored in a sealed container (Scheme 1, Step(ii)).

\section{Characterization of pDA-g-pMTAC coating}

Attenuated total reflectance-Fourier transform infrared (ATR-FTIR) spectrometry. The pDA-BiBBr and pDA- $g$-pMTAC 
Step (i)<smiles>CCCCCCCCCc1ccc(O)c(O)c1</smiles>
(DA)

Step (ii)

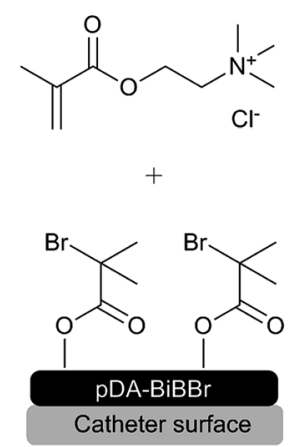

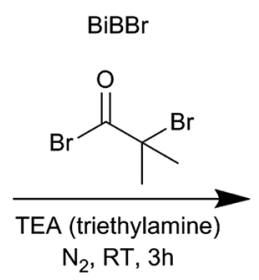

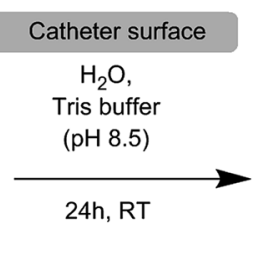

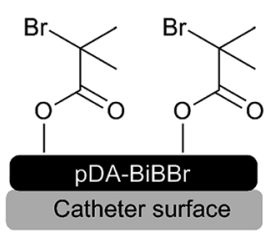

Scheme 1 Method for modification of catheter surfaces. Step (i), reaction of BiBBr with DA, followed by polymerization of DA-BiBBr onto the catheter surface. Step (ii), grafting pMTAC to pDA-BiBBr via ARGET-ATRP.

coatings on the catheter samples were characterized by ATRFTIR spectroscopy using a Perkin Elmer Spectrum 400 fitted with a zinc selenide ATR crystal. An uncoated catheter was used as background. Samples were placed onto the crystal, and sufficient force (approximately $140 \mathrm{~N}$ ) was used to detect spectra which were detected over a range of $600 \mathrm{~cm}^{-1}$ to $3500 \mathrm{~cm}^{-1}$, with a resolution of $4.00 \mathrm{~cm}^{-1}$ and 16 scans per run.

Water contact angle (WCA). WCA measurements were only performed on pDA- and pDA-g-pMTAC-coated glass slides as the curvature of the catheters made this technique difficult. Triplicate measurements on the glass slides were conducted in air via the static sessile drop method using an OCA 15 plus (Dataphysics). Water droplets $(5 \mu \mathrm{L})$ were analyzed for contact angle using SC 20 software (minimum six drops per sample).

\section{Evaluation of anti-biofouling activity of pDA-g-pMTAC coating}

Adherence of bacteria to catheters. Bacterial strains, Escherichia coli and Pseudomonas aeruginosa, were isolated from urine samples by SA Pathology, Flinders Medical Centre (South Australia, Australia). Bacteria were grown in $10 \mathrm{~mL}$ Brain Heart Infusion (BHI) broth (Thermo Fisher Scientific, Victoria, Australia) at $37^{\circ} \mathrm{C}$ with shaking for $16 \mathrm{~h}$. Following coating, catheter segments were sterilised in $70 \%$ ethanol and air-dried. Bacterial adherence and biofilm development was performed essentially as described previously for intravenous catheters. ${ }^{33}$ Briefly, catheter pieces were placed in $30 \mathrm{~mL} 1 \times 10^{8} \mathrm{cfu} \mathrm{mL}^{-1}$ E. coli, 1 $\times 10^{8} \mathrm{cfu} \mathrm{mL}^{-1}$ P. aeruginosa, or BHI broth, for $3 \mathrm{~h}$ at $37^{\circ} \mathrm{C}$ to allow initial bacterial attachment to occur. Catheter pieces were washed with PBS pH 7.4 and transferred to fresh BHI broth and incubated for a further $48 \mathrm{~h}$ at $37^{\circ} \mathrm{C}$ to permit biofilm formation. Catheter pieces were removed and washed 5 times in PBS
pH 7.4 with gentle inversion, prior to fixing for EM or enumeration of bacterial counts.

Scanning electron microscopy (SEM). The adhered bacteria and associated biological substances were fixed to the catheter surface by incubation in $1 \mathrm{~mL}$ aqueous $4 \%$ paraformaldehyde for $30 \mathrm{~min}$ at room temperature. The fixed catheter pieces were stored in PBS $/ 0.02 \%$ sodium azide at $4{ }^{\circ} \mathrm{C}$. Catheters were dried using stepwise dehydration by increasing ethanol concentration, using $10 \mathrm{~min}$ incubations in each of 30,50, 70, 85, and $90 \%$ ethanol, followed by two sequential $100 \%$ ethanol incubations. Catheters were then air dried for $48 \mathrm{~h}$ prior to sputter coating with gold for $30 \mathrm{~s}$ at $35 \mu \mathrm{A}$ (Quorumtech KQ300T D or Quorumtech K757X). Bacterial attachment to the external surfaces of the catheters was assessed using a scanning electron microscope (SEM; Camscan MX2500) with a spot size of 4, a 10 $\mathrm{kV}$ accelerating voltage, a 60-70 $\mu \mathrm{A}$ beam current, a $20-30 \mathrm{~mm}$ working distance and $3.1 \mathrm{~K}$ magnification. Images shown are representative of at least three replicates.

Colony counts. Adherent bacteria and associated biological substances were detached from the surface of the catheter pieces by sonication in $1 \mathrm{~mL}$ BHI broth in a sonicating water bath (Bransonic Ultrasonic Cleaner, Danbury, CT, USA) for 10 min and vortexing for $30 \mathrm{~s}$. The resulting suspension was serially diluted to $1 \times 10^{-5}$ in BHI broth, and $100 \mu \mathrm{L}$ of each dilution was spread on TSA plates and incubated at $37^{\circ} \mathrm{C}$ for $24 \mathrm{~h}$. Macroscopic bacterial colonies were counted by eye.

\section{Biocompatibility assays}

Inductively-coupled plasma mass spectrometry (ICP-MS). Residual copper left on the catheter surface after the ARGETATRP was analyzed using an Agilent 7500 ICP-MS. Pre-weighed, 
uncoated, or pDA- $g$-pMTAC coated catheter samples were treated to determine copper content. Samples were partially digested prior to ICP-MS analysis by heating to $100{ }^{\circ} \mathrm{C}$ for $1.5 \mathrm{~h}$ in concentrated $\mathrm{HNO}_{3}$, cooling to room temperature, then adding $\mathrm{H}_{2} \mathrm{O}_{2}(0.5 \mathrm{~mL})$ and heating at $100{ }^{\circ} \mathrm{C}$ for $1 \mathrm{~h}$ before cooling to room temperature. As partial digestion resulted in the majority of the catheter being digested as well as the coating, fresh samples were incubated in $\mathrm{HNO}_{3}(5 \mathrm{~mL} ; 20 \%$ (v/ $\mathrm{v})$ ) for $3 \mathrm{~h}$ prior to analysis by ICP-MS for a leaching assay.

Cell culture. Vero and HEK-293 (ATCC, Manassas, VA) cell lines were maintained in DMEM (HyClone ${ }^{\circledR}$, Thermo Fisher Scientific Inc, USA) with $10 \%$ (v/v) FBS and $200 \mathrm{mM}$ L-glutamate at $37{ }^{\circ} \mathrm{C}$ and $5 \% \mathrm{CO}_{2}$.

Biocompatibility of coatings on glass slides. Uncoated, pDABiBBr-, or pDA- $g$-pMTAC-coated glass slides were placed in the wells of a tissue culture plate and seeded with vero cells in DMEM maintenance media for $72 \mathrm{~h}$ at $37^{\circ} \mathrm{C}$ and $5 \% \mathrm{CO}_{2}$ before growth assays.

Leaching assay of coated catheters. Uncoated, pDA-BiBBr-, or pDA- $g$-pMTAC-coated catheter sections were affixed to the lid of a 24-well tissue culture plate such that the coated catheter was suspended in culture medium without touching the cells adhering to the plate. HEK293 cells $\left(7.5 \times 10^{4}\right.$ cells per well $)$ were incubated in the presence of the catheter sections for $72 \mathrm{~h}$ at $37{ }^{\circ} \mathrm{C}$ and $5 \% \mathrm{CO}_{2}$ prior to growth assays. Viable and dead cells were measured using a trypan blue exclusion assay. ${ }^{\mathbf{3 4}, 35}$ Cell viability assays are representative of at least two independent experiments.

Biocompatibility of MTAC monomer. HEK293 and vero cells were plated at $7.5 \times 10^{4}$ cells per well, and MTAC was added to the cells in a $1: 2$ dilution series from $53 \mathrm{mg} \mathrm{mL}^{-1}$ MTAC to 0.05 $\mathrm{mg} \mathrm{mL}^{-1}$.

\section{Results and discussion}

\section{Surface coatings}

Silicone coated latex catheters were modified by grafting pMTAC from a pDA-attached initiator (Scheme 1). The synthesis strategy consists of the attachment of a $\mathrm{BiBBr}$ initiator to a surface using pDA. The initiator was then used to graft the MTAC monomer from the surface via ARGET-ATRP. The coating was designed so that the quaternary ammonium functionality of pMTAC engrafted in the coated catheters could serve as an active antibacterial and anti-biofouling moiety. In the synthesis of pDA coatings organic solvents such as DMF are often required; $;^{31,32}$ however, this partially destroyed the catheters, and an aqueous based method had to be developed. The method was initially optimized using glass slide surfaces, where the successful surface attachment and subsequent polymerization was shown using ATR-FTIR spectroscopy and water contact angle measurements (Fig. 1, S1 and S2, and Table S1 $\dagger$ ). Subsequently, catheter pieces were used and analyzed for their surface functionalization and antimicrobial properties.

Urinary catheters were cut into pieces, coated with pDABiBBr and pDA- $g$-pMTAC, and analyzed by ATR-FTIR spectroscopy (Fig. 1). The presence of the pDA-BiBBr initiator coating can be seen by a broad peak at $3260 \mathrm{~cm}^{-1}$, which is

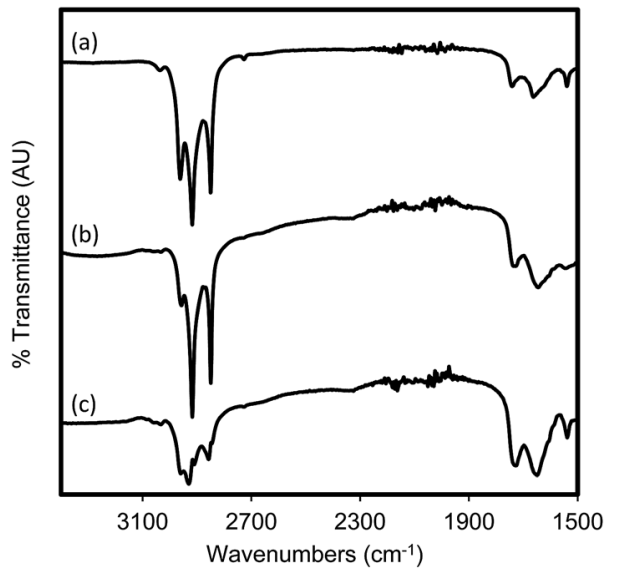

Fig. 1 ATR-FTIR spectra of catheter sections which were (a) untreated, (b) coated in pDA-BiBBr and (c) coated in pDA-g-pMTAC.

characteristic of the catechol group of pDA (Fig. S1 $\dagger$ ). ${ }^{31,32}$ The successful coating with pDA-g-pMTAC is supported by the increased intensity of characteristic bands between $2800 \mathrm{~cm}^{-1}$ and $2900 \mathrm{~cm}^{-1}$, in addition to a reduction in intensity of those noted for the uncoated catheter. ${ }^{31}$ Note the reduction in transmittance, with a broad peak at approximately $3260 \mathrm{~cm}^{-1}$, due to catechol groups of pDA. This peak is slightly reduced by the pDA- $g$-pMTAC coating, compared to the uncoated control. Additional peaks can be seen between 2800 and $3000 \mathrm{~cm}^{-1}$. The peaks are quite consistent between the uncoated sections and the pDA-coated sections, but are quite different in the pDA- $g$ pMTAC-coated sections. Most notably, the $2911 \mathrm{~cm}^{-1}$ peak can be attributed to symmetric stretching of the methyl groups, and this peak differs from the other peaks present in the uncoated catheters.

WCA measurements on pDA-BiBBr-coated glass slides were not significantly different from pDA-g-pMTAC-coated or uncoated glass slides, as was expected (Fig. S2 and Table S1 $\dagger$ ). ${ }^{31}$ Glass slides, pDA and pDA- $g$-pMTAC are all hydrophilic, ${ }^{31,36}$ and the absence of change in WCA confirms a deposition of hydrophilic coating on glass.

\section{Evaluation of anti-biofouling activity of pDA-g-pMTAC coating}

pDA-g-pMTAC-coated and uncoated catheter pieces were incubated with two different bacterial isolates from urinary tract infections, E. coli and $P$. aeruginosa, and the attachment of bacteria to the catheter surface was analyzed using SEM (Fig. 2) and colony counts (Fig. 3). Both E. coli and P. aeruginosa showed a substantial adherence to uncoated catheters after $48 \mathrm{~h}$ incubation (Fig. 2), with considerable biofouling visible on catheters incubated with $P$. aeruginosa (Fig. 2E). Control experiments in the absence of any bacteria showed no bacterial attachment on either coated or uncoated catheters (Fig. 2A and B). On the pDA- $g$-pMTAC-coated catheters and regardless of the bacterial species used, very few bacteria were observed, and these were present as isolated cells only, with no detectable patches of adjoining cells or associated material (Fig. 2C and D). These results were supported by the 

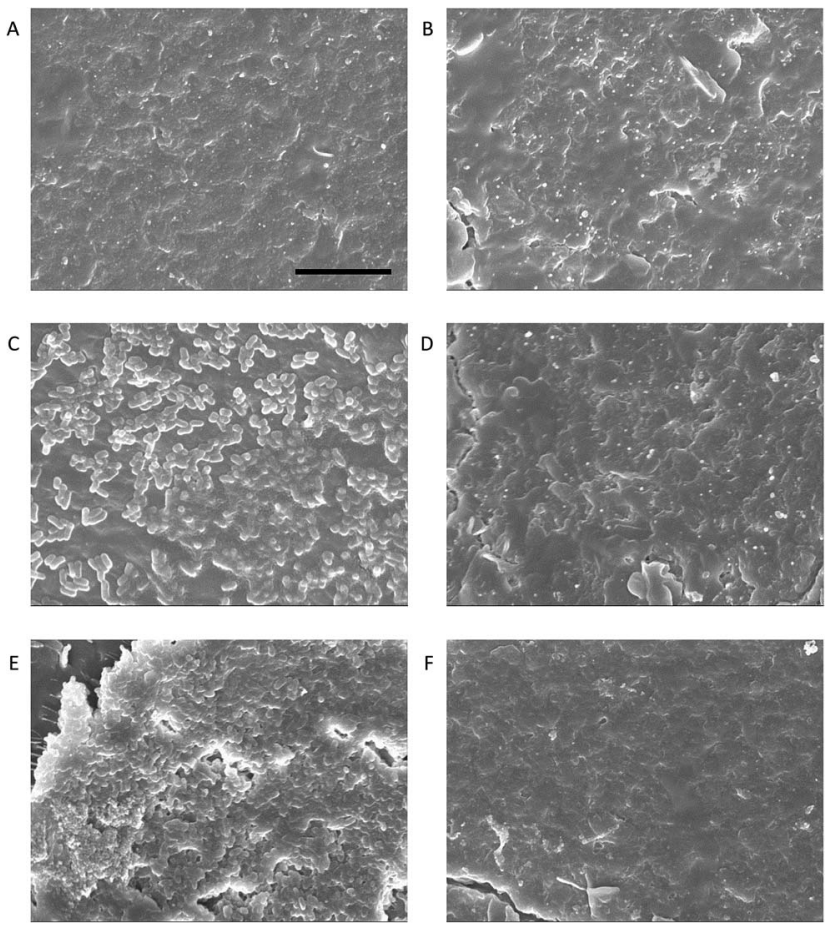

Fig. 2 PDA-g-pMTAC coating reduces biofouling of catheters exposed to $E$. coli or $P$. aeruginosa. Uncoated $(A, C, E)$ and coated $(B, D$, F) catheters were exposed to media only (A, B), E. coli (C, D), or $P$. aeruginosa $(\mathrm{E}, \mathrm{F})$ for $48 \mathrm{~h}$ prior to preparation for imaging by SEM. The scale bar for all images is $10 \mu \mathrm{m}$.
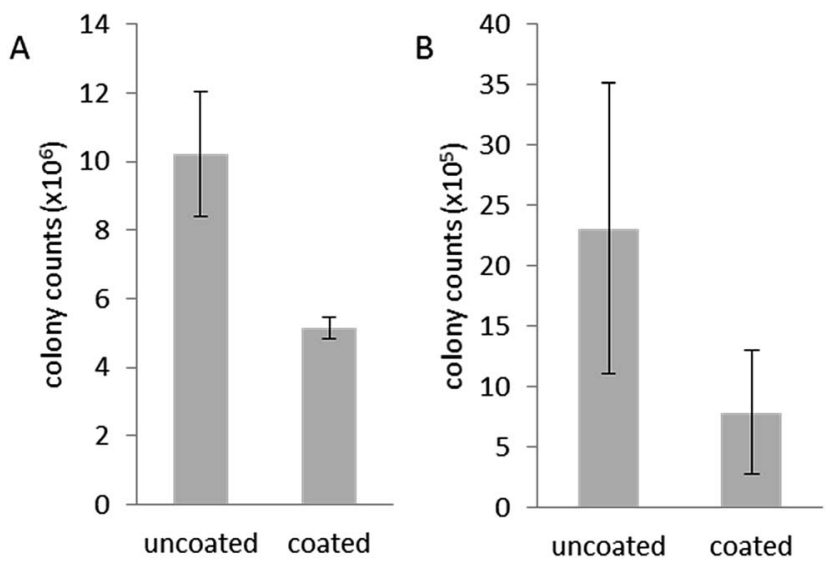

Fig. 3 Colony count results indicate that fewer colonies can be grown from coated catheters incubated with $E$. coli (A) or $P$. aeruginosa (B) for $48 \mathrm{~h}$ compared to uncoated catheters. Error bars are standard error of the mean.

corresponding colony counts, in which fewer colonies grew from coated catheter sections than uncoated catheter sections (Fig. 3 and Table S2†). For E. coli, a 50\% reduction and for $P$. aeruginosa, a $90 \%$ reduction in adherence in two of three colony count assays could be observed. These results show a significant improvement compared to most previously reported polymeric coatings. ${ }^{29,37}$

\section{Biocompatibility of pDA-g-pMTAC coatings}

In addition to antibacterial properties, a coating designed for medical applications must be non-toxic to the host. The ARGET-ATRP polymerization requires $\mathrm{Cu}(\mathrm{I})$ as a catalyst, which can be toxic to human and bacterial cells. The levels of copper in prepared catheter pieces was therefore analyzed using ICP-MS, and no difference in copper levels was detected in treated or untreated catheter samples (Table 1), indicating no significant retention of copper in the pDA-g-pMTAC coating.

The biocompatibility of the coating was investigated by exposing the coatings to cells typically used in similar assays. ${ }^{38}$ Vero cells were grown on glass slides, which were either uncoated, coated with pDA-BiBBr alone or with pDA-g-pMTAC (Fig. 4). pDA-g-pMTAC coated samples were not expected to cause cell toxicity as pMTAC has been used as a cell patterning agent for neuronal cells. ${ }^{39}$ Indeed, on pDA-g-pMTAC coatings, cells grew as well as those on a tissue culture plate, an ideal surface for vero cell growth (Fig. 4A and D).

Cells are known to not adhere or divide well on glass surfaces, and did not grow well on glass in the current study. They also did not grow well on the pDA-BiBBr surface. pDA is a naturally occurring polymer that has adherent properties; ${ }^{26}$ however, it is possible that the $\mathrm{Br}$ of the pDA-BiBBr coated surfaces inhibited vero cell growth.

In order to determine whether the coatings were leaching potentially toxic substances, catheter sections were suspended

Table 1 ICP-MS results for Cu levels in uncoated and pDA-g-pMTAC coated catheter both digested and leached

\begin{tabular}{llll}
\hline Process & Sample & $\mathrm{Cu}\left(\mathrm{mg} \mathrm{kg}^{-1}\right)$ & Stdev \\
\hline \multirow{2}{*}{ Digested } & Uncoated & 2.7 & 0.31 \\
& Coated & 3.2 & 0.15 \\
Leached & Uncoated & $8.1 \times 10^{-5}$ & $4.0 \times 10^{-5}$ \\
& Coated & $1.0 \times 10^{-4}$ & $2.9 \times 10^{-5}$
\end{tabular}
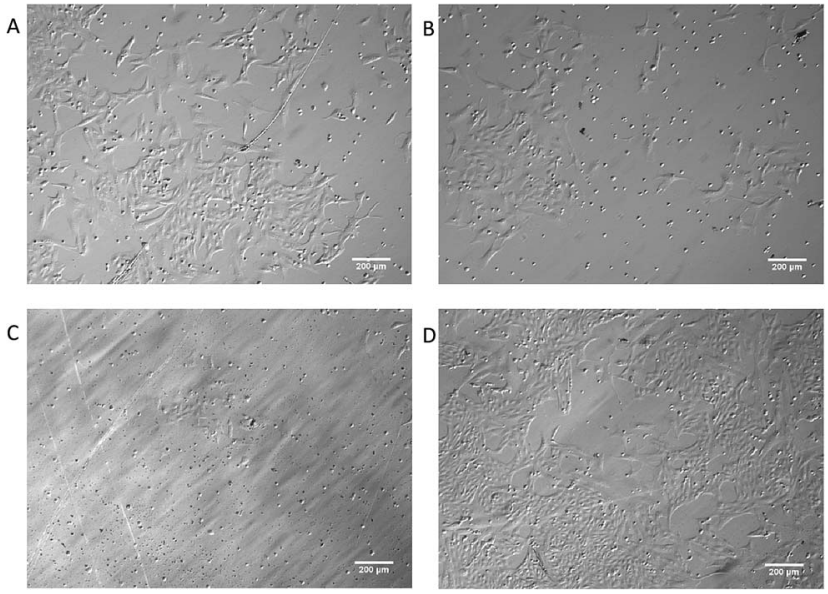

Fig. 4 PMTAC coating is not cytotoxic to eukaryotic cells. Vero cells were grown on $(A)$ tissue culture plates and $(B-D)$ treated glass slides. Glass slides were (B) uncoated or (C) coated with pDA-BiBBr, or (D) pDA-g-pMTAC. 

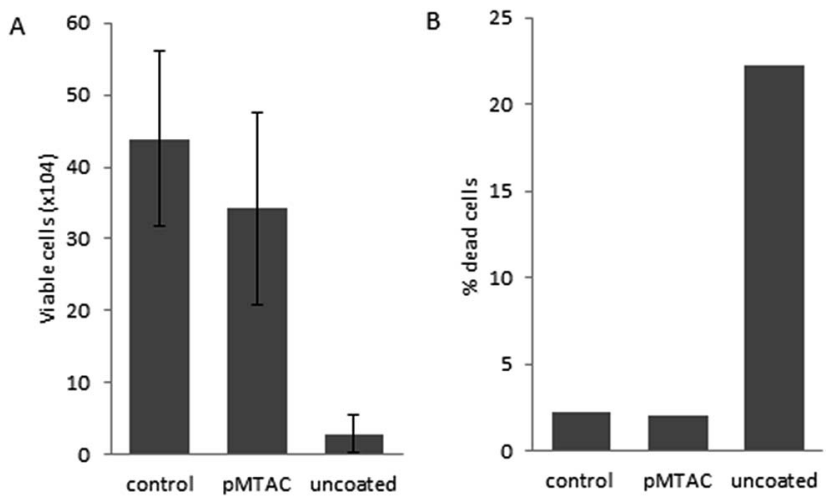

Fig. 5 Exposure to pDA-g-pMTAC coating does not alter cell viability of HEK293 cells. The effect on (A) cell viability and (B) cell death after exposure to catheters for $48 \mathrm{~h}$ was measured using the trypan blue cell exclusion assay. Error bars are $+/$ - standard deviation from at least 2 replicates, and representative of two technical replicates.

for three days in cell culture media above HEK293 cells which were adhered to tissue culture plates. Cell viability and death were not significantly altered in cells exposed to pDA-g-pMTAC coated catheters compared to untreated cells (Fig. 5). However, there was a $92 \%$ reduction in cell viability and 11 -fold increase in cell death in cells exposed to uncoated silicone catheters compared to those exposed to pDA-g-pMTAC coated catheters. This is likely due to latex toxicity, as cutting the catheter exposed the latex core inside the silicone outer shell which could leach toxins into the media ${ }^{40}$ Additional biocompatibility testing of the MTAC monomer, at concentrations up to $13 \mathrm{mg} \mathrm{mL}^{-1}$ in cell culture media (or one quarter of the initial concentration of MTAC at the beginning of the polymerization reaction), indicated that MTAC did not affect cell viability of HEK293 or vero cells (data not shown). Furthermore, the reaction product of MTAC polymerization added in a suspension of HEK293 cells does not alter the number of viable cells (data not shown).

\section{Conclusions}

A novel anti-biofouling pDA- $g$-pMTAC coating has been developed and used on silicone-coated urinary catheters. A high efficacy against colonization by clinical bacterial isolates while providing a suitable surface for eukaryotic (host) cell attachment and proliferation could be shown. The coating thus provides an interesting architecture for medical implants. The favourable cell adhesion may be exploited in future studies for anti-biofouling surfaces which require cellular adhesion for the host to accept the implant.

\section{Acknowledgements}

Flinders Analytical is acknowledged for support of the ICP-MS experiments. Partial funding was provided by the Repat Foundation, Flinders University and the Flinders Centre for Nanoscale Science and Technology. Julie Calvert is acknowledged for TC cell maintenance.

\section{References}

1 J. Gallo, M. Holinka and C. S. Moucha, Int. J. Mol. Sci., 2014, 15, 13849-13880.

2 M. Ribeiro, F. J. Monteiro and M. P. Ferraz, Biomatter, 2012, 2, 176-194.

3 C. L. Abad and N. Safdar, Infectious Disease Special Edition, 2011, 84-98.

4 K. Matyjaszewski and N. V. Tsarevsky, Nat. Chem., 2009, 1, 276-288.

5 J. L. Pariente, L. Bordenave, F. Jacob, R. Bareille, C. Baquey and M. Le Guillou, Eur. Urol., 2000, 38, 640-643.

6 I. Pomfret, Nurs. Stand., 2000, 14, 46-51.

7 F. Furno, K. S. Morley, B. Wong, B. L. Sharp, P. L. Arnold, S. M. Howdle, R. Bayston, P. D. Brown, P. D. Winship and H. J. Reid, J. Antimicrob. Chemother., 2004, 54, 1019-1024.

8 J. R. Johnson, B. D. Johnston, M. A. Kuskowski and J. Pitout, J. Urol., 2010, 184, 2572-2577.

9 G. Regev-Shoshani, M. Ko, A. Crowe and Y. Av-Gay, Urology, 2011, 78, 334-339.

10 R. Gutierrez-Gonzalez and G. R. Boto, J. Infect., 2010, 61, 920.

11 S. Noimark, C. W. Dunnill, M. Wilson and I. P. Parkin, Chem. Soc. Rev., 2009, 38, 3435-3448.

12 R. Pickard, T. Lam, G. MacLennan, K. Starr, M. Kilonzo, G. McPherson, K. Gillies, A. McDonald, K. Walton, B. Buckley, C. Glazener, C. Boachie, J. Burr, J. Norrie, L. Vale, A. Grant and J. N'Dow, Lancet, 2012, 380, 1927-1935.

13 D. G. Desai, K. S. Liao, M. E. Cevallos and B. W. Trautner, J. Urol., 2010, 184, 2565-2571.

14 L. Islas, C. Alvarez-Lorenzo, B. Magariños, A. Concheiro, L. F. d. Castillo and G. Burillo, Int. J. Pharm., 2015, 488, 20-28.

15 J. Shenderovich, M. Feldman, D. Kirmayer, A. Al-Quntar, D. Steinberg, E. Lavy and M. Friedman, Int. J. Pharm., 2015, 485, 164-170.

16 I. P. S. Thome, V. S. Dagostin, R. Piletti, C. T. Pich, H. G. Riella, E. Angioletto and M. A. Fiori, Mater. Sci. Eng., C, 2012, 32, 263-268.

17 P. Kurt, L. Wood, D. E. Ohman and K. J. Wynne, Langmuir, 2007, 23, 4719-4723.

18 P. J. McCubbin, E. Forbes, M. M. Gow and S. D. Gorham, J. Appl. Polym. Sci., 2006, 100, 381-389.

19 A. Bello, M. M. Quinn, M. J. Perry and D. K. Milton, Environ. Health, 2009, 8, 11.

20 I. Yudovin-Farber, J. Golenser, N. Beyth, E. I. Weiss and A. J. Domb, J. Nanomater., 2010, 2010, DOI: 10.1155/2010/ 826343.

21 X. Ding, C. Yang, T. P. Lim, L. Y. Hsu, A. C. Engler, J. L. Hedrick and Y.-Y. Yang, Biomaterials, 2012, 33, 65936603.

22 Z. X. Voo, M. Khan, K. Narayanan, D. Seah, J. L. Hedrick and Y. Y. Yang, Macromolecules, 2015, 48, 1055-1064.

23 A. L. Hook, C.-Y. Chang, J. Yang, J. Luckett, A. Cockayne, S. Atkinson, Y. Mei, R. Bayston, D. J. Irvine, R. Langer, 
D. G. Anderson, P. Williams, M. C. Davies and M. R. Alexander, Nat. Biotechnol., 2012, 30, 868-875.

24 D. Mahata, S. M. Mandal, A. Basak and G. B. Nando, RSC Adv., 2015, 5, 69215-69219.

25 A. Roosjen, W. Norde, H. C. van der Mei and H. J. Busscher, Prog. Colloid Polym. Sci., 2006, 132, 138-144.

26 H. Lee, S. M. Dellatore, W. M. Miller and P. B. Messersmith, Science, 2007, 318, 426-430.

27 Y. B. Lee, Y. M. Shin, J.-h. Lee, I. Jun, J. K. Kang, J.-C. Park and H. Shin, Biomaterials, 2012, 33, 8343-8352.

28 R. Wang, K. G. Neoh, E.-T. Kang, P. A. Tambyah and E. Chiong, J. Biomed. Mater. Res., Part B, 2015, 103, 519-528.

29 R. Wang, K. G. Neoh, Z. Shi, E.-T. Kang, P. A. Tambyah and E. Chiong, Biotechnol. Bioeng., 2012, 109, 336-345.

30 D. R. Dreyer, D. J. Miller, B. D. Freeman, D. R. Paul and C. W. Bielawski, Chem. Sci., 2013, 4, 3796-3802.

31 A. J. Blok, R. Chhasatia, J. Dilag and A. V. Ellis, J. Membr. Sci., 2014, 468, 216-223.

32 B. Zhu and S. Edmondson, Polymer, 2011, 52, 2141-2149.

33 J. L. Kadurugamuwa, L. Sin, E. Albert, J. Yu, K. Francis, M. DeBoer, M. Rubin, C. Bellinger-Kawahara, J. T. R. Parr and P. R. Contag, Infect. Immun., 2003, 71, 882-890.
34 V. C. Thompson, T. K. Day, T. Bianco-Miotto, L. A. Selth, G. Han, M. Thomas, G. Buchanan, H. I. Scher, C. C. Nelson, B. Australian Prostate Cancer, N. M. Greenberg, L. M. Butler and W. D. Tilley, Int. J. Cancer, 2012, 131, 662-672.

35 L. M. Butler, D. B. Agus, H. I. Scher, B. Higgins, A. Rose, C. Cordon-Cardo, H. T. Thaler, R. A. Rifkind, P. A. Marks and V. M. Richon, Cancer Res., 2000, 60, 5165-5170.

36 S. Yeo, T. Kwon, C. Choi, H. Park, J. W. Hyun and D. Jung, Curr. Appl. Phys., 2006, 6, 267-270.

37 A. Pradhan, N. Pradhan, L. Sukla, P. Panda and B. Mishra, Bioprocess Biosyst. Eng., 2014, 37, 139-149.

38 N. C. Ammerman, M. Beier-Sexton and A. F. Azad, in Current Protocols in Microbiology, John Wiley \& Sons, Inc., 2005, DOI: 10.1002/9780471729259.mca04es11.

39 R. Dong, R. P. Molloy, M. Lindau and C. K. Ober, Biomacromolecules, 2010, 11, 2027-2032.

40 J. L. Pariente, L. Bordenave, F. Jacob, R. Bareille, C. Baquey and M. Le Guillou, Eur. Urol., 2000, 38, 640-643. 